\section{The mediating role of competitive orientation in determining self-construal in unethical decision-making}

The mediating role of competitive orientation

\author{
D.M. Sachinthanee Dissanayake \\ Department of Commerce, Faculty of Management Studies and Commerce, \\ University of Sri Jayewardenepura, Nugegoda, Sri Lanka
}

Received 22 May 2021 Revised 5 September 2021 19 November 2021 Accepted 2 December 2021

\begin{abstract}
Purpose - The ethics literature has focused on the influence of self-construal dimensions on unethical decision-making. However, the literature is unclear about why these self-construal dimensions (Independentself, Relational-self, Collective-self) impact differently on unethical decision-making. Based on the theory of cooperation and competition, this study empirically examines the mediating role of competitive orientation and addresses the theoretically unexplained question of why self-construal dimensions influence differently on unethical decision-making.

Design/methodology/approach - Based on the deductive approach, a quantitative research study was conducted on the Sri Lankan banking industry because there have been many instances of unethical behavior reported in this sector lately. Data were collected from 305 bank branch managers using a structured survey questionnaire.

Findings - The findings revealed that competitive orientation mediates the self-construal dimensions and explained that competitive orientation is one reason why independent-self, relational-self and collective-self influence differently on unethical decision-making.

Originality/value - This paper addresses the unanswered question of why self-construal dimensions relate to unethical decision-making differently.
\end{abstract}

Keywords Self-construal, Independent-self, Relational-self, Collective-self, Unethical decision-making,

Competitive orientation

Paper type Research paper

\section{Introduction}

Employees often engage in actions which may benefit the individual but cause harm to society. For instance, if an employee is given the freedom to report on his/her attendance or time spent on work or on a project without being monitored by the organization, that employee may misrepresent facts rather than report them accurately in order to maximize his/her benefits over the benefits of the company. Similarly, in order to win a negotiation, an employee could deceive another to achieve a more favorable outcome for himself/herself or for the company. These types of individual actions like cheating, lying and dishonesty violate social norms, and are therefore regarded as unethical (Gino et al., 2011; Treviño et al., 2014).

Ethical decisions are those associated with socially accepted norms (Beu et al., 2003; Jones, 1991; Kish-Gephart et al., 2010; Simpson et al., 2020), while unethical decisions go against societal norms (Jones, 1991; Treviño et al., 2014). In order to make ethical decisions,

(C) D.M. Sachinthanee Dissanayake. Published in European Journal of Management Studies. Published by Emerald Publishing Limited. This article is published under the Creative Commons Attribution (CC BY 4.0) licence. Anyone may reproduce, distribute, translate and create derivative works of this article (for both commercial and non-commercial purposes), subject to full attribution to the original publication and authors. The full terms of this licence maybe seen at http://creativecommons.org/licences/by/4.0/ legalcode

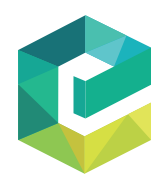

European Journal of Management Vol. 27 No. 1,2022 pp. $39-60$ Emerald Publishing Limite e-ISSN: 2635-2648 p-ISSN: 2183-4172 DOI 10.1108/EJMS-05-2021-0045 
EJMS

27,1

individuals have to make them by aligning with the interests of other actors in society (Bull and Ridley-Duff, 2019; Cojuharenco et al., 2012). Therefore, clearly, how close you are to others or how you define yourself in terms of your relationships with others (extent of independent and interdependent self-construal) plays a major role in deciding your unethical or ethical behavior (Cojuharenco et al., 2012; Gino and Galinsky, 2012; Hoyt and Price, 2015; Markus and Kitayama, 1991). The interdependent-self broadly represents the relational and collective selves (Cross et al., 2011).

According to research, persons who have higher interdependent self-construal, as opposed to those who have lower interdependent self-construal, have a greater propensity toward making ethical decisions (Bellé and Cantarelli, 2017; Cojuharenco et al., 2012; Hoyt and Price, 2015; van Prooijen and van den Bos, 2009). Although researches have focused on examining the self-construal theory in unethical decision-making (Cojuharenco et al., 2012; Dhandra and Park, 2017; Hoyt and Price, 2015), the unethical decision-making literature does not go beyond the above explanation, and the fundamental research question remains unanswered, why self-construal levels differently influence unethical decision-making. Based on the theory of cooperation and competition (Deutsch, 1949), the current researcher argues that the independent-self individuals incline to make unethical decisions as they have competitive orientation due to the focus on personal goal achievement, while those with an interdependent self-construal generally eschews competition and work in cooperation with others, so they resist from making unethical decisions. Competitive orientation is the individual's inclination to perform better than others (Chen et al., 2011), and it has been found to influence unethical decision-making (Kilduff et al., 2016; Kilduff and Galinsky, 2017; Li et al., 2018). The theory of cooperation and competition specifies that an individual will be competitive to achieve personal goals and collaborate to achieve common goals (Deutsch, 1949). Therefore, the current researcher aims to present competitive orientation as a reason why self-construal dimensions influence unethical decision-making.

This research study makes several contributions: first, the researcher contributes to the selfconstrual literature by broadening the scope of its predictive ability with regard to unethical decision-making by providing further explanation as to why self-construal dimensions influence unethical decision-making. In this study, the researcher examines competitive orientation as the mediating mechanism between self-construal dimensions (independent self, relational self and collective self) and unethical decision-making in answering the above research question. Second, despite the fact that competition plays such a large part in human behavior, for both good and bad, studies on competitiveness are surprisingly rare (Swab and Johnson, 2019). Scholars have examined competitive orientation widely in the sports environment (e.g.: Albouza, 2021; Ives et al., 2020) and in childhood education (e.g.: Nebel et al., 2016) but not adequately in the working environment, specifically on the dark side of competitive orientation (Kilduff et al., 2016; Li et al., 2018).

This study is a state-of-the-art investigation into unethical decision-making that provides evidence from Sri Lanka. Sri Lanka has been identified as a country with a high rate of corruption as per the Corruption Perception Index 2016, where it is ranked 95 (Transparency International, 2020; Jayawardena-Willis et al., 2021). Since researchers have conducted selfconstrual research in East Asia and in Western countries (eg: Hoshino-Browne et al., 2005; Kitayama et al., 2004, 2006; Markus and Kitayama, 1991), studying the self-construal phenomenon in a developing country in South Asia, such as Sri Lanka, will add value to the literature on self-construal. Furthermore, Sri Lanka has a culture that includes both individualism and collectivism among different social groups categorized under educational level, occupational level and socioeconomic status (Freeman, 1997; Kumarasinghe and Hoshino, 2010). Since culture is the fundamental base for self-construal (Triandis, 1996), it would be interesting to investigate corporate behavior in relation to self-construal and unethical decision-making in Sri Lanka as a mix of individualism and collectivism. 
The remainder of the paper is structured as follows: the next section presents the literature review and hypothesis development followed by the methodology of the study. Thereafter, the researcher presents the data analysis and the results. Finally, the results are discussed and the contribution of the findings to theory and practice is set down, as well as the limitations of the study.

\section{Literature review and hypotheses development}

\subsection{Unethical decision-making}

The field of ethical decision-making broadly represents both ethical and unethical decisionmaking/behaviour (see: Treviño et al., 2006, 2014). The general understating is that ethical decisions are good and unethical decisions are bad, and any understanding of the predictors of ethical or unethical decision-making should help to reduce more of the latter and less of the former. Unethical behavior in organizations is related to the concepts of workplace deviance and illegal behavior, but deviance and illegal behavior are not synonyms for unethical behavior (see: Kish-Gephart et al., 2010). Jones (1991) defined an ethical decision as "a decision that is both legal and morally acceptable to the larger community" and an unethical decision as "either illegal or morally unacceptable to the larger community" (p. 367). Rest's (1986) definition discusses how people judge the conflict of interests among individuals and how they coordinate their actions and cooperate with one another to enhance human welfare. Here, Rest (1986) has viewed ethics as a social value. By considering these definitions, an ethical decision can be defined as a decision that should benefit the larger society during a dilemma related to a moral issue.

Furthermore, researchers have studied three levels of outcomes related to a behavior: "unethical behavior that is contrary to accepted moral norms in society (e.g. lying, cheating, stealing), routine ethical behavior that meets the minimum moral standards of society (e.g. honesty, treating people with respect) and extraordinary ethical behavior that goes beyond society's moral minima (e.g. charitable giving, whistleblowing)" (Treviño et al., 2006, pp. 636637). In this article, the researcher limits to the two former categories when discussing unethical/ethical decisions because extraordinary ethical behavior cannot be expected generally from all the members in the organization and it goes beyond the minimum accepted behavior. Therefore, the researcher defines theft, lying, sabotage, misrepresentation of financial statements and any type of dishonest behavior as unethical decision-making.

\subsection{Competitive orientation}

Competitive orientation is the urge to perform in a more superior manner than others to exploit personal interests (Chen et al, 2011). It is the motive that spurs individuals to strive against others to achieve and excel. Competition is now considered to be an essential part of an individual's life (Rigdon and D'Esterre, 2015), but it is a learned behavior rather than something inherent in human nature (Kohn, 1986). The ancient Greeks considered competition as a means of establishing social superiority which makes individuals compete with rivals in their chosen field of expertise (Benzi, 2016). The winners of these competitions rose to fame and glory, while the losers fell into obscurity. People compete for limited resources (e.g.: money), services and status (e.g.: promotions, prestige) (Swab and Johnson, 2019). Competitiveness can be beneficial, characterized by increased involvement and motivation, or unhealthy, characterized by distrust and intense negative feelings, depending on how it develops (Johnson and Johnson, 1991).

According to the theory of cooperation and competition, cooperation is often examined as opposed to competition, and many scholars have conceptualized competition and cooperation as two ends of one continuum (e.g. Deutsch, 1949; Deutsch, 1962; Rapoport et al., 1965). Mead (1976) defined cooperation as "the act of working together to one end" and competition as

The mediating role of competitive orientation 
EJMS

27,1

"the act of seeking to gain what another is endeavoring to gain at the same time" (p. 8), indicating the tendency towards not working together. Competitive orientation has differential impacts on individuals' cognition and behavior (Chen et al., 2011; Rigdon and D'Esterre, 2015; Swab and Johnson, 2019). In social comparison theory, it is highlighted that competitive people are more likely to emphasize self-improvement or self-value (Kilduff et al., 2010). From a positive point of view, competition encourages individuals to work harder to achieve better results. Therefore, in the business domain, competition often leads to quality products, price reduction and reduced production time (Rigdon and D'Esterre, 2015). However, the problem is that competitive orientation often encourages individual to make unethical decisions (Li et al., 2018; Rigdon and D'Esterre, 2015).

2.2.1 Competitive orientation and unethical decision-making. According to the theory of cooperation and competition, negative attitudes such as "we are against one another" and "we seek to enhance our own power by reducing the power of the others" are established (Deutsch, 2006, p. 25). The competitive mindset pushes individuals to work harder and achieve more, and it can easily encourage cheating by encouraging the perpetrator to break established rules (Rigdon and D'Esterre, 2015). In Schwieren and Weichselbaumer's (2010) experimental research, competitors were given a task to solve mazes within $30 \mathrm{~min}$ and the winner was declared to be the person who could solve the most mazes within the given time. Participants in this experiment engaged in cheating in order to win. This study showed that in a competitive environment, ethical decisions will not be given priority, instead, benefits and rewards will be the focus. Further, competitive orientation in a person may reduce his/her awareness of rules and regulations which may lead him/her to breach ethical conduct. Similarly, the study of Fischbacher and Follmi-Heusi (2013) has suggested that people do lie to sustain the way they are seen by themselves and others, which shows that the competitive mindset pushes people to maintain the position they hold in society. For this reason, it is normal for many firms to make false statements in advertising just to push ahead of others (see: Barigozzi et al., 2009; Rhodes and Wilson, 2018). According to Kilduff et al. (2016), actors who are experiencing rivalry are more prone to participate in the kind of conduct that embodies the negative aspects of competition, such as deception, cheating, and sabotage. Therefore, the competitive mindset does play a major role in dishonest behavior and can be supposed to have a positive effect on unethical decisionmaking. Based on the above discussion, the following hypothesis is advanced:

H1a. Higher levels of competitive orientation positively influences unethical decisionmaking.

\subsection{Self-construal}

Self-construal describes how individuals understand themselves in relation to others and answers the question, "who am I?" (Cross et al., 2011; Markus and Kitayama, 1991). Selfconstrual is also referred to as self-concept and self-identity (Yang et al., 2020) and describes a "constellation of thoughts, feelings, and actions concerning one's relationship with others" (Singelis, 1994, p. 581). According to the self-construal literature, there are three dimensions of self-definition: the independent-self, the relational-self, and the collective-self (Cross et al., 2011; Sedikides and Brewer, 2015). The independent-self considers himself/herself to be independent of others and stresses individual uniqueness and distinctiveness. In contrast, the relational-self and the collective-self emphasize relationships with others and with a collective group membership, respectively (Brewer and Gardner, 1996; Turner et al., 1987). Therefore, these self-construal types denote three distinct ways of defining the self in relation to others in psychological relationships. Although there are different levels of construal that can be viewed as contrasting concepts, an individual may possess some aspects of each dimension to different degrees (Markus and Kitayama, 1991; Yang et al., 2020). Markus and Kitayama (1991), Singelis (1994) and Triandis (1989) argued that culture promotes different construal 
levels. For example, Western cultures and Asian cultures, by and large, promote individualself construal and interdependence-self construal, respectively (Cross et al., 2011). Individualism and Collectivism may often be confused with self-construal. However, they should be carefully distinguished, where the former is used to describe individuals and the latter to describe cultures. The construal types can influence cognition, emotion, motivation and behavior when one dimension dominates over and above the other two dimensions (Markus and Kitayama, 1991; Yang et al., 2012, 2020). Most importantly, self-construal research has explained that independence and interdependence play an important part in explaining attitudes and behaviors (e.g.: Brutus and Greguras, 2008; Wiekens and Stapel, 2008). Studies demonstrate that the dimensions of self-construal have different impacts on workplace attitudes and behaviors such as negotiation behavior (Gelfand et al., 2006), individual well-being (Cross and Morris, 2003), organizational support and knowledge sharing (Yang et al., 2020), innovation behavior (Zhang et al., 2021) and unethical behavior (Cojuharenco et al., 2012).

\subsection{The independent-self}

The independent-self is conceptualized as an autonomous person and a unique entity, who has less association with others (Markus and Kitayama, 1991; Utz, 2004). Markus and Kitayama (1991) have given similar labels to this self-construal type such as "individualist, egocentric, separate, autonomous, idiosyncratic, and self-contained" (p. 226). In the independent-self, one's self, as independent from others, wants to protect the view of personality as a unique set of traits (Markus, 1977). Researchers identify individuals who are high in independent-self to be creative (Goncalo and Staw, 2006), but explain that they find it difficult to understand others' emotions.

2.4.1 The independent-self and unethical decision-making. Those with an independent selfconstrual, when making decisions, are less likely to consider social norms and the impact of their actions on others. Since it is important that a person makes ethical decisions, that person should be aware about social norms and moral standards (Rest, 1986). However, the independent-self is associated with lower levels of moral awareness (Cojuharenco et al., 2012) and this leads to lower levels of prominence given by the decision maker to aligning with social norms when making decisions. This could lead to lower levels of ethical decisions due to the lower moral awareness of these individuals with independent self-construal. Furthermore, researchers argue that independent-self individuals are generally less empathetic (Cojuharenco et al., 2012; Johnson and Chang, 2006), and less empathetic people pay little attention to align with the interests of others when making decisions. Cross and Madson (1997) have pointed out that "for these persons, individual rights, goals, and wishes are the primary basis for moral choices. The goals and needs of society, family members, or others are secondary or subordinate ...." (p. 7). Moreover, the independent-self does not consider how his/her decisions will affect others, meaning that people with this form of self-construal will focus more on how decisions affect themselves. Therefore, it is unlikely that these decisions would benefit society as a whole; rather, the individualistic decisions could harm society and violate ethics. Interestingly, it has been found that independent-self leaders often blame their subordinates for failures (Deng et al., 2020). This emphasizes the fact that independent-self individuals are slow to take responsibility for the decisions they make, and are quick to pass the blame on to others. Evidently, the consequences of their irresponsible acts will not make them realize the extent of social harm caused and may not influence them to avoid such behavior. Empirical evidence on this relationship can be found in Cojuharenco et al. (2012) and Wan et al. (2021) who have empirically examined how psychological closeness reduces tourists' unethical behaviors. In line with these arguments, the following hypothesis is suggested.

H2a. Higher levels of independent self-construal positively influence unethical decisionmaking.

The mediating role of competitive orientation 
EJMS

27,1

2.4.2 The independent-self and competitive orientation. Competitive orientation is the intention to compete with another to exploit personal benefits (Chen et al., 2011). Independentself individuals are considered to be working towards self-enhancement and self-achievement (Yang et al., 2020), and they are guided primarily by self-interest and personal goals (Simpson et al.,2018). Rather than meeting the expectations of their in-groups, they aim for achievement that has personal meaning for them (Singelis, 1994). Furthermore, in contrast to persons with an interdependent-self, persons with independent self-construal interpret the context of choices as opportunities to demonstrate their uniqueness (Kim and Markus, 1999). Independent-self individuals also present themselves as risk-seekers (Zhang and Mitta, 2007). These arguments and findings suggest that the psychologies of these individuals are tuned to be ahead of others, meaning that these independent-self construal individuals have a mindset favoring competitiveness. According to an empirical study conducted by Utz (2004), these individuals have lower levels of cooperation than those with interdependence-selves. Similarly in the study of Yang et al. (2020), the independent-self is not involved in knowledge sharing as he/she does not favor common goals. Accordingly, the following hypothesis is constructed.

$H 2 b$. Higher levels of independent self-construal positively influence competitive orientation.

\subsection{The relational-self}

The relational-self differs from the independent self in its motivation to protect, enhance and initiate relationships (Cross et al., 2000). Significant dyadic ties are used to define the relational-self. These types of relationships include teacher-student, supervisorsubordinate, parent-child, romantic relationships or friendships (Brewer and Gardner, 1996; Cross et al., 2000; Sedikides and Brewer, 2015). A greater level of relational-self is linked to an increased preference towards relational goals and interpersonal interactions (Johnson and Chang, 2006). Markus and Kitayama (1991) have pointed out that "experiencing interdependence entails seeing oneself as part of an encompassing social relationship and recognizing that one's behavior is determined, contingent on, and to a large extent, organized by what the actor perceives to be the thoughts, feelings, and actions of others in the relationship" (p. 227). Researchers use interdependency to interpret the relational self and the collective self (Cross et al., 2000). However, Kashima et al. (1995) have found that the relational and collective self are empirically separable. Gabriel and Gardner (1999) have also examined this demarcation, who discussed the extent to which these two types of interdependencies describe how the American men and women differ. They discovered that American women were more likely than males to define themselves in relationship terms, but that men were more inclined to describe themselves in terms of broader, group collectives, using a number of approaches. This result was further validated by Yuki et al. (2005) in a cultural setting where East Asian in-groups were found to be built on relational links (emphasizing the relationalself), whereas Western groups were found to be based on categorical distinctions between ingroups and out-groups (emphasizing the collective-self). Therefore, it is noteworthy that the relational-self focuses more on close relationships while the collective-self focuses more on groups and collectives.

2.5.1 The relational-self and unethical decision-making. Ties of personal attachment provide the foundation for the relational self. As mentioned earlier, such relationships include parent-child, romantic affiliations, and friendships (Sedikides and Brewer, 2015). This type of self-representation is based on the reflected evaluation process and is linked to the goal of safeguarding or strengthening the significant other while also preserving the relationship (Brewer and Gardner, 1996; Sedikides and Brewer, 2015). When a person describes himself/ herself as relational, he/she is more sensitive to other people's thoughts and feelings 
(Lee et al., 2019), and they are more "caring and supportive of close others" (Cross et al., 2002, p. 400). Furthermore, reciprocal advantage and mutual interest become more apparent as a result of relational self-construal, and the individual is motivated to take the other's interests seriously. Therefore, the relational-self may resist acting in ways that are harmful to others, and show greater awareness of social norms when making decisions, an attitude which will encourage ethical decisions. This is also evident in the study of Cojuharenco et al. (2012). In addition, the relational-self encourages pro-social behavior, where strong emotional attachment to recipients was found to boost pro-social motivation (Ferenczi et al., 2017; Grant, 2008; Zhou et al., 2021). Zhou et al. (2021) conducted an experimental study to examine how the relational-self encourages pro-social behavior, and results have revealed that higher levels of relational-self have a stronger influence on prosocial behavior. According to Jones (1991), the psychological proximity between beneficiaries and donors decreases the severity of a moral dilemma and increases the likelihood of engaging in ethical activities. Consequently, the following hypothesis is constructed.

$H 3 a$. Higher levels of relational self-construal negatively influence unethical decisionmaking.

2.5.2 The relational-self and competitive orientation. According to extant research, persons who have a high interdependent self-construal, as opposed to those who have a low interdependent self-construal, have a greater concern for justice in their relationships with others (Gollwitzer and Bucklein, 2007; van Prooijen and van den Bos, 2009). Individuals who have an interdependent self-concept consider the needs of their interactive partners. As a result, persons with prominent interdependent self-construal are predicted to have higher levels of cooperation than people with prominent independent-self construal. Utz (2004) has examined this and found that interdependence promotes cooperation because of social value orientation. Therefore, a greater focus on relationships results in individuals who do not compete with others, but instead cooperate with them. Based on these empirical works, the following hypothesis is advanced:

$H 3 b$. Higher levels of relational self-construal negatively influence competitive orientation.

\subsection{The collective-self}

The collective-self is the other type of self-construal discussed under the broad area of interdependent self-construal. Individuals with high degrees of collective-self identify themselves in terms of belonging to a group rather than to specific connections (Cojuharenco et al., 2012). Kashima and Hardie (2000) stated that the collective self is "also referred to as the social or socio-centric self, referring to self-definitions derived from one's memberships in groups or social categories” (p. 20). Specifically, the collective self is made up of characteristics of the self-concept that distinguishes in-group individuals from relevant out-group members (Sedikides and Brewer, 2015). The collective self is built on impersonal ties to others formed from common (and frequently symbolic) group identifications. These ties do not necessitate close personal relationships among members of the organization.

2.6.1 The collective-self and unethical decision-making. Greater levels of collective-self are linked to stronger commitment to group goals and as a result, there is a higher likelihood for social obligations to be met. Larger degrees of collective-self have been linked to increased sensitivity to social norms. Therefore, these people honor rules and generally conduct themselves in a pro-social manner. Also, a greater level of collective-self is related with higher levels of interpersonal citizenship (Johnson and Chang, 2006). Triandis et al. (2001) found that collective-self persons disagree with dishonesty in negotiations within the group. Collectiveself was also found to have a strong relationship with altruistic citizenship behavior (Roney
The mediating role of competitive orientation 
EJMS

27,1

and Soicher, 2021), and altruistic citizenship behavior is considered to be behavior that goes beyond society's moral minima (Treviño et al., 2014). Similarly, Cojuharenco et al. (2012) have revealed the negative association between the collective-self and unethical behavior. Individual or collective self-construal on a micro level, as well as the impact of individualistic and collectivistic cultures on a macro level, have both been highlighted as key factors in unethical or ethical decision-making, respectively (Abraham and Pane, 2014; Ralston et al., 2014; Saracevic and Schlegelmilch, 2021). According to the above arguments, the following hypothesis is constructed:

$H 4 a$. Higher levels of collective self-construal negatively influence unethical decisionmaking.

2.6.2 The collective-self and competitive orientation. When a person identifies himself/herself as a collective-self, they act cooperatively towards the group and devote their energy and time towards group success (Tyler and Blader, 2003). The more the individual's identification with the group, the more vital it is for the group to prosper. Carnevale et al. (2019) have pointed out that a leader with collective identity engages in helping behavior. This is because the sense of self is greatly linked to the group. According to Barreto and Ellemers (2000), people who identify strongly with a group may be counted on to strive for the group's improvement. Therefore, the collective-self person's mindset is such that it desires to cooperate instead of competing. The following hypothesis is derived based on the preceding arguments.

H4b. Higher levels of collective-self construal are related with lower levels of competitive orientation.

2.6.3 Mediation of competitive orientation on the relationship between self-construal and unethical decision-making. As mentioned above, past research indicates that competitive orientation is an important variable of self-construal. According to the previous discussion, the theory of self-construal (Markus and Kitayama, 1991) and the theory of cooperation and competition (Deutsch, 1949), it can be supposed that self-construal is linked to competitive orientation. Also, self-construal relates to unethical decision-making. These relationships suggest the indirect relationship of self-construal with unethical decision-making. For the best of researcher's knowledge, the past researchers have not studied this indirect relationship before and the current researcher suggests that competitive orientation is a significant mediator of the relationship between self-construal and unethical decisionmaking.

Individualism is believed to drive people to focus inward on their own interests at the expense of other people's interests. The fear is that as long as individuals are focused on achieving personal objectives and living according to personal beliefs, they will be unable or unwilling to cooperate to satisfy shared needs. Thus, the independent-self would resist cooperation, and instead, will be competitive. Horney (1937) explained that competition is the reason for interpersonal conflict, where interpersonal conflicts never benefit society as a whole. People who are characterized by the independent-self do not collaborate with others and may even engage in counterproductive behaviors (Johnson and Lord, 2010). Therefore, the independent-self will be competitively oriented and such an orientation will not encourage ethical decisions. Based on the above arguments, the following hypothesis is formulated:

$H 5 a$. Competitive orientation mediates the influence of independent self-construal on unethical decision-making.

Cooperation is at the other end of the continuum from competition (e.g. Deutsch, 1962; Rapoport et al., 1965). Since the current researcher argues that self-construal relates to unethical decision-making due to competitive orientation, it can be specifically postulated that the relational-self and collective-self associate negatively with competitive orientation 
and thus, decrease the level of unethical decision-making. People with a high interdependentself are more attentive to other people and sensitive to others, and injustices to others are more likely to be perceived as injustices to themselves (van Prooijen and van den Bos, 2009). In addition, people who have strong interdependent identities show a greater willingness to cooperate with other parties because collaborations are not believed to carry risks of social rejection or exploitation (Lind, 2001). Therefore, when people are interdependent, such mutuality activates cooperation that cultivates fairness and justice to others. Under these circumstances, it is more likely that the interdependent-self (both relational and collective self), due to lower levels of competitive orientation, will more likely engage in ethical decisionmaking. Accordingly, following hypotheses are constructed:

$H 5 b$. Competitive orientation mediates the influence of relational self-construal on unethical decision-making.

$H 5 c$. Competitive orientation mediates the influence of collective self-construal on unethical decision-making.

Based on the above hypotheses following framework was developed (see Figure 1).

\section{Methodology}

\subsection{Participants and procedures}

The participants of this research study consisted of branch managers of commercial banks in Sri Lanka. Branch managers of commercial banks were selected because there have been many publicly reported incidents on unethical decisions made by bank branch managers. There are 2,876 commercial bank branches in Sri Lanka (Central Bank of Sri Lanka, 2018) and the sample size was chosen to be 350 based on Krejcie and Morgan (1970). A questionnairebased survey was used to collect data.

Before the main survey, the researcher ensured the validity and reliability of the survey instrument by conducting a pilot survey. A pilot survey is important to eliminate potential issues that may arise during the main survey (Saunders et al., 2009). The pilot survey was conducted using a convenience sample of 30 managers working in the banking and financial industry in Sri Lanka using a self-administered survey questionnaire. In ensuring face validity, the researcher solicited comments from experts on the readability, clarity and suitability to the context of the questionnaire. The researcher also performed the reliability test using Cronbach's alpha by analyzing the data via IBM's Statistical Package for the Social Sciences (SPSS) 20.0 software. The validity and reliability analysis indicated that there was no need for further revisions.

The researcher administered 350 questionnaires to a sample of branch managers who represented all commercial banks in Sri Lanka. The questionnaires were proportionately

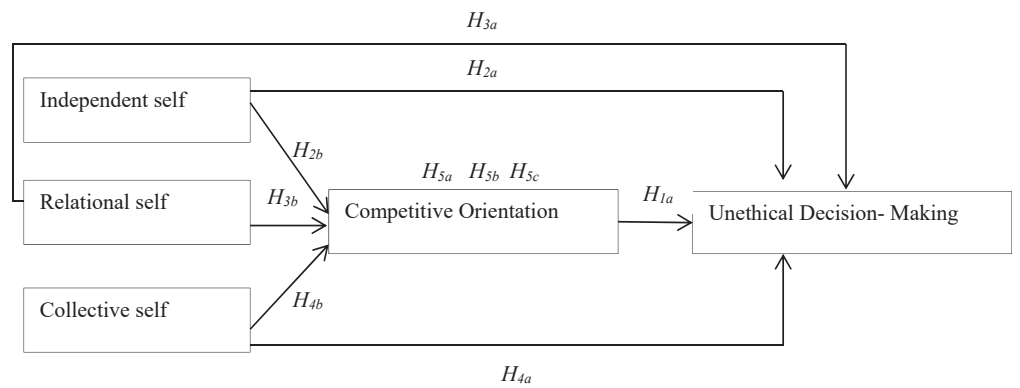

Figure 1.

Framework of the study 
EJMS

27,1

allocated based on the total number of branches that each bank has, and then, the convenience sampling method was used to distribute the questionnaire. The researcher personally administered the survey questionnaire together with a return envelope. This was preceded by making calls to managers and following-up. The researcher received 307 questionnaires, out of which 2 were incomplete. Therefore, the response rate was $87 \%$. Females comprised $47 \%$ $(n=142)$ of the sample and males made up $53 \%(n=163)$. The majority of participants were aged between 28 years and 45 years, and this segment accounted for more than $70 \%$ of the total sample. $97 \%$ of the respondents had more than 6 years of work experience.

Since this research used self-reported measures, social desirability bias and common method bias were clear concerns (Conway and Lance, 2010). In mitigating these issues, the researcher followed the recommendations provided by Podsakoff et al. (2003) when designing the questionnaire. The covering letter to the questionnaire emphasized that there were no correct or wrong answers and encouraged honesty by emphasizing confidentiality and by not mentioning ethics in the instructions. The survey questionnaire guaranteed the anonymity of the respondent branch manager and of his/her respective bank. In addition, with the aim of reducing social desirability biases, the researcher specifically mentioned that the results would only be used for academic purposes (Nancarrow et al., 2001). In the questionnaire, the researcher separated the predictors and criterion variables to ensure unrelated parts of topic areas in order to reduce common method bias. Perhaps due to effective post-hoc controls, Harman's one-factor test (Podsakoff et al., 2003) revealed that the first factor did not account for a majority of the variance in the data, and suggested that there were no common method bias issues in the data. The researcher performed an independent sample $t$-test to identify whether there was any difference between early respondents and late respondents (Lindner et al., 2001). Results revealed that there was no significant difference, emphasizing that nonresponse bias was not a problem for the results.

\subsection{Measures}

3.2.1 Self-construal. Levels of the self-concept scale were used in measuring self-construal (Johnson and Lord, 2010; Johnson and Chang, 2006). This scale comprisesthree dimensions to measure the three levels of self-concept and was used in the study of Cojuharenco et al. (2012), which is related to unethical behavior. Therefore, present study also used the same scale to measure self-construal. Each of these dimensions include 5 items, and thus, a total of fifteen statements (Refer Annexure 1) were used on a 1-5 Likert-type scale (1 = strongly disagree; $5=$ strongly agree). As was evident in previous studies (Cojuharenco et al., 2012), in this study also, the reliabilities of all three dimensions were at acceptable levels (Independent-self $\alpha=0.79$, Relational-self $\alpha=0.86$ and Collective-self $\alpha=0.78$ ).

3.2.2 Competitive orientation. Competitive orientation was measured via six items drawn from Chen et al. (2011). Participants conveyed their degree of agreement/disagreement with the six items on a $1-5$ Likert-type scale $(1=$ strongly disagree; $5=$ strongly agree). Sample items included "I feel somewhat disappointed when others perform better than me" and "Sometimes, I view a contest as an opportunity for me to show that I am better than others" $(\alpha=0.76)$.

3.2.3 Unethical decision-making. Similar to earlier business ethics research, this study also relied on a vignette to measure unethical decision-making (Fritzsche and $\mathrm{Oz}, 2007$; Peterson, 2004). The vignette was adapted from Hoyt and Price (2015) and was adjusted as follows to suit the banking industry with the help of two experienced bank managers and two senior academics.

Imagine that your organization has announced a business plan competition for employees to come up with innovative ideas to strengthen business operations in the organization, and you have decided to participate in this competition. You are required to present a plan that could be 
implemented in the organization. The best plan will win the competition and the presenter of the best plan will obtain an opportunity to work as an adviser to the top management during the implementation of the plan. The winner will be awarded a huge cash price and will also be paid an additional allowance for being the adviser.

After reading the vignette, participants indicated their responses to the scenario on a six-item questionnaire (refer Annexure 2) measured on a 1-5 Likert-type scale (1 = strongly disagree; $5=$ strongly agree) (Hoyt and Price, 2015). Sample items included: "I would be willing to pass on incorrect information to other groups if it gave us a competitive advantage" and "I would be willing to engage in what some might say are sneaky tactics" $(\alpha=0.87)$.

\section{Data analysis}

The structural equation modeling (SEM) technique using partial least squares (PLS) with SmartPLS 3.0 software was utilized to analyze the data. PLS-SEM is one of the most completely developed techniques and has become a crucial tool for academics to study diverse social science topics (Latan et al., 2017). In PLS-SEM, testing for normal distribution is not required as it is a nonparametric method. However, sample size and collinearity assumptions need to be considered. The minimum sample size should be equal to "10 times the maximum number of arrowheads pointing at a latent variable anywhere in the PLS path model" (Hair et al., 2017, p. 25). According to this rule, the sample size in this research met the minimum sample requirements.

The PLS-SEM path analysis comprises a two-way approach (Henseler et al., 2009). These are the assessments of the measurement model and the assessment of the structural model. Hair et al. (2019) differentiated the specifications related to formative and reflective indicators. The current model comprises only reflective measurements.

In assessing the measurement model (refer Table 1), Cronbach's alpha $(>0.6)$ and composite reliability ( $>0.7)$ were used to ensure internal consistency (Hair et al., 2017). Convergent validity was ensured using indicator loading $(>0.7)$ and average variance extracted (AVE) (>0.5) (Hair et al., 2017). The researcher also tested for discriminant validity using the heterotrait-monotrait ratio (HTMT), which met the recommended criterion of $<0.9$ for all variables (refer Table 2) (Hair et al., 2017).

After ensuring that all the variables and indicators were reliable and valid, the next step was to assess the structural model results and to test the hypotheses. As specified by Hair et al. (2017), the structural model was assessed using the variance inflation factor (VIF), coefficients of determination $\left(R^{2}\right)$, effect size $\left(f^{2}\right)$ and predictive relevance $\left(Q^{2}\right)$. The results of the structural model are given in Table 3 . The VIF values for all the independent variables in the model are $<3.3$, indicating that there was no collinearity problem between the predictor variables. The coefficient of determination $\left(R^{2}\right)$ indicated that unethical decision-making can be explained by the predictor variables being between 0.307 and 0.325 , indicating a reasonable level of predictive power. Furthermore, the effect size values showed small to medium effects (ranging from 0.041 to 0.233 ) from the predictor variables. The predictive

\begin{tabular}{lcccr}
\hline Variable & Factor loading range & Alpha & Composite reliability & AVE \\
\hline Independent_self & $0.766-0.853$ & 0.798 & 0.820 & 0.589 \\
Relational_self & $0.855-0.884$ & 0.862 & 0.880 & 0.598 \\
Collective_self & $0.752-0.842$ & 0.786 & 0.842 & 0.614 \\
Unethical_decision-making & $0.678-0.862$ & 0.867 & 0.898 & 0.602 \\
Competitive_orientation & $0.758-0.852$ & 0.763 & 0.814 & 0.569
\end{tabular}

The mediating role of competitive orientation 
EJMS

27,1

50
Table 2.

Discriminant validity results and correlation values

\section{Hypotheses testing and results}

PLS-SEM was used to conduct hypothesis testing in this study. Table 4 comprises findings on the path coefficient related to the direct hypotheses (bootstrapping results for 5,000 subsamples). In line with expectations, competitive orientation positively affected unethical decision-making $(\beta=0.322 ; p=0.003)$, confirming Hypothesis 1a. In support of Hypothesis $2 \mathrm{a}$, the independent-self positively impacted unethical decision-making $(\beta=0.278 ; p<0.05)$, as it did competitive orientation $(\beta=0.201 ; p<0.001)$, in support of Hypothesis $2 \mathrm{~b}$.

relevance (Stone-Geisser $Q^{2}$ ) value generated for the endogenous variable is $>0$, ensuring that the model has predictive relevance.

\begin{tabular}{lccccccc}
\hline Variable & Mean & SD & 1 & 2 & 3 & 4 & 5 \\
\hline 1. Independent_self & 3.10 & \pm 0.89 & 1 & 0.686 & 0.543 & 0.591 & 0.671 \\
2. Relational_self & 4.21 & \pm 0.72 & 0.15 & 1 & 0.621 & 0.781 & 0.691 \\
3. Collective_self & 4.04 & \pm 0.68 & 0.09 & $0.45^{* *}$ & 1 & 0.604 & 0.733 \\
4. Unethical_decision-making & 2.88 & \pm 1.09 & $0.19^{*}$ & $-0.21^{* *}$ & $-0.32^{*}$ & 1 & 0.648 \\
5. Competitive_orientation & 3.79 & \pm 0.96 & $0.23^{*}$ & $-0.42^{* *}$ & $-0.41^{* *}$ & $0.38^{* * *}$ & 1
\end{tabular}

Note(s): $* p<0.05 ; * *<<0.01$

Above the diagonal elements are the HTMT values

Below the diagonal elements are the correlations between the variables
Table 3.

Results of the structural model

\begin{tabular}{lccccc}
\hline Variable & $R^{2}$ & Adj. $R^{2}$ & $F^{2}$ & $Q^{2}$ & VIF \\
\hline Independent_self & - & - & 0.041 & - & 1.558 \\
Relational_self & - & - & 0.233 & - & 2.852 \\
Collective_self & - & - & 0.229 & - & 2.689 \\
Unethical_decision-making & 0.307 & 0.304 & & 0.431 & - \\
Competitive_orientation & 0.325 & 0.321 & & 0.321 & - \\
\hline
\end{tabular}

Table 4.

Hypotheses testing: direct path

\begin{tabular}{lcccl}
\hline & $\begin{array}{c}\beta \\
\text { coefficient }\end{array}$ & $p$-value & $\begin{array}{c}\text { Bootstrapping } \\
t \text {-value }\end{array}$ & Decision \\
\hline Structural path & 0.322 & $0.003^{* *}$ & 9.421 & $\begin{array}{l}\text { H1a } \\
\text { supported }\end{array}$ \\
\hline Competitive_Orientation $\rightarrow$ UDM & 0.278 & $0.012^{*}$ & 17.296 & $\begin{array}{l}\text { H2a } \\
\text { supported }\end{array}$ \\
$\begin{array}{l}\text { Independent_self } \rightarrow \text { UDM } \\
\text { Independent_self } \rightarrow \text { H2b }\end{array}$ & 0.201 & $0.008^{* *}$ & 14.499 & $\begin{array}{l}\text { supported } \\
\text { Competitive_orientation }\end{array}$ \\
$\begin{array}{l}\text { Relational_self } \rightarrow \text { UDM } \\
\text { Relational_self } \rightarrow\end{array}$ & -0.241 & $0.001^{* *}$ & 7.281 & $\begin{array}{l}\text { Ha } \\
\text { supported }\end{array}$ \\
$\begin{array}{l}\text { Competitive_orientation } \\
\text { Collective_self } \rightarrow \text { UDM }\end{array}$ & -0.160 & $0.022^{*}$ & 8.477 & $\begin{array}{l}\text { H3b } \\
\text { supported }\end{array}$ \\
Collective_self $\rightarrow$ Competitive_orientation & -0.213 & $0.002^{* *}$ & 12.322 & $\begin{array}{l}\text { H4a } \\
\text { supported } \\
\text { supported }\end{array}$ \\
Note(s): UDM: unethical decision-making; $* p<0.05 ; * * p$ & $<0.01$ & & 9.298 &
\end{tabular}


Hypothesis 3a and 3b were also supported as the relational-self impacted negatively on unethical decision-making $(\beta=-0.241 ; p=0.001)$ and competitive orientation $(\beta=-0.160$; $p=0.022)$. Finally, both Hypothesis $4 \mathrm{a}$ and $4 \mathrm{~b}$ were supported negatively as the collectiveself- associated negatively with unethical decision-making $(\beta=-0.285 ; p<0.001)$ and with competitive orientation $(\beta=-0.213 ; p<0.001)$.

The procedure outlined by Baron and Kenny (1986) was used to test the mediating hypotheses and to investigate the existence of a mediating relationship. Initially, the direct relationships between the independent-self and unethical decision-making, the relational-self and unethical decision-making and the collective-self and unethical decision-making were tested separately using three models. All the tests showed significant relationships: Independent-self $\rightarrow$ $\operatorname{UDM}(\beta=0.435 ; p=0.000 ; t$-value $=32.725)$, Relational_self $\rightarrow \operatorname{UDM}(\beta=-0.441 ; p=0.000$; $t$-value $=22.825)$, Collective_self $\rightarrow \mathrm{UDM}(\beta=-0.531 ; p=0.000 ; t$-value $=19.835)$. Next, for the test of mediation, these models were run for all direct and indirect paths related to the hypotheses. Further, VAF (variance accounted for) values were calculated to assess whether the mediations are full or partial mediations. Table 5 summarizes the results of the mediating hypotheses, where all the hypotheses were supported.

\section{Discussion and conclusion}

This research examines the mediating effect of competitive orientation to determine as to why self-construal influences unethical decision-making. A cross sectional study carried out on bank branch managers in Sri Lanka evidences that self-construal influences unethical decisionmaking directly as it does indirectly through the mediating mechanism of competitive orientation.

Bank branch managers' independent-self positively affected unethical decision-making and this is consistent with the empirical results of the study by Cojuharenco et al. (2012) and the explanation provided by Bellé and Cantarelli (2017) in the meta-analysis. Wan et al. (2021) explained that when a person is psychologically distant from others, they tend to misbehave at a cost to others. A similar explanation can be furnished regarding bank branch managers who showed greater levels of independent-self. When managers define themselves independently from others, these managers and other workers may have distant psychological relationships, reducing the former's awareness of social norms. Moreover, competitive orientation is a reason for these independent bank branch managers to make unethical decisions. As highlighted in the self-construal theory (Markus and Kitayama, 1991), the independent self is more oriented towards personal goal achievement and it could even be at the expense of socially accepted norms.

\begin{tabular}{|c|c|c|c|c|c|}
\hline Structural path & $\begin{array}{c}\beta \\
\text { coefficient } \\
\end{array}$ & $p$-value & $\begin{array}{c}\text { Bootstrapping } \\
t \text {-value }\end{array}$ & $\begin{array}{c}\text { VAF } \\
\text { values }\end{array}$ & Mediation \\
\hline $\begin{array}{l}\text { Independent_self } \rightarrow \\
\text { Competitive_orientation } \rightarrow \text { UDM }\end{array}$ & 0.186 & $0.015^{*}$ & 15.756 & $33 \%$ & $\begin{array}{l}\text { Partial } \\
\text { mediation }\end{array}$ \\
\hline $\begin{array}{l}\text { Relational_self } \rightarrow \\
\text { Competitive_orientation } \rightarrow \text { UDM }\end{array}$ & -0.123 & $0.009 * *$ & 19.851 & $28 \%$ & $\begin{array}{l}\text { Partial } \\
\text { mediation }\end{array}$ \\
\hline $\begin{array}{l}\text { Collective_self } \rightarrow \\
\text { Competitive_orientation } \rightarrow \text { UDM }\end{array}$ & -0.225 & $0.001 * *$ & 27.339 & $42 \%$ & $\begin{array}{l}\text { Partial } \\
\text { mediation }\end{array}$ \\
\hline
\end{tabular}

Note(s): UDM: unethical decision-making; $\beta$ Coefficient, $p$-values and $t$ values related to indirect path of each dimension of self-construal to UDM; $* p<0.05 ; * * p<0.01$

VAF: variance accounted for
The mediating role of competitive orientation

51 
EJMS

27,1

Relational self-construal levels related negatively with unethical decision-making for bank branch managers, as postulated. Similar results were found in Cojuharenco et al. (2012) for samples of working adults. In addition to unethical decision-making in general, Cojuharenco et al. (2012) have also specifically linked the relational-self negatively with cheating behavior. In the study of Ferenczi et al. (2017) and Zhou et al. (2021), the relationalself was found to associate with pro-social behavior due to these people's close relationships with others. Thus, the ethical behavior of relational-self individuals is at a higher level, even beyond society's moral minima (Treviño et al., 2014). Apart from a specific reference to the relational-self, researchers have also conducted studies under the broad topic of the interdependent self and unethical decision-making, the results of which also align with the results of the current study (Gollwitzer and Bucklein, 2007; Hoyt and Price, 2015). The current research extends this understanding even further by explaining that the relational self-construal negatively relates to unethical decision-making due to a relative lack of competitive orientation. As argued, relational self-construal works more towards common success and people with relational self-construal do not generally violate social norms.

As was found in the study of Cojuharenco et al. (2012), the current study also established that greater the collective self-construal, greater will be the awareness of social norms and lesser will be the propensity to make unethical decisions. Parallel research done on prosocial behavior and citizenship behavior has further verified this relationship (Johnson and Chang, 2006; Roney and Soicher, 2021). Some macro-level research on collectivism at the business level has also revealed similar results (Ralston et al., 2014). Furthermore, research also confirms that individuals with higher levels of collective-self resist making unethical decisions because of a relative lack of competitive orientation. Overall, the current research empirically supports the explanation given in the self-construal theory (Markus and Kitayama, 1991), where the independent self was postulated to promote personal goals while the interdependent-self was postulated to promote cooperation with others in achieving common goals.

\subsection{Theoretical implications}

Firstly, although many researchers have indicated that self-construal affects a person's unethical behavior (e.g.: Cojuharenco et al., 2012; Hoyt and Price, 2015), according to the knowledge of the researcher, no studies have investigated the impact of the intervening variable competitive orientation on self-construal and unethical decision-making, something which will go a long way towards explicating why independence and interdependence influence unethical behavior differently. Therefore, the results of this study enrich the selfconstrual as well as the ethics literature. Secondly, the need for a deeper understanding of competitive orientation is emphasized, especially of the antecedents of competitive orientation (Chen et al., 2011), even though very few research studies have responded to these calls (Kilduff et al., 2016; Li et al., 2018). This study has highlighted that a person with an independent self-construal will focus on competition, whereas the relational-self and collective-self will not. Therefore, this finding extends the scope of previous research on competitive orientation by providing a more comprehensive account of self-construal. Moreover, few research studies have investigated the role of competitive orientation in explaining unethical decision-making, and thus, the relationship between competitive orientation and unethical decision-making has, by and large, lacked empirical support. Therefore, this research study makes an important contribution by empirically testing the aforementioned relationship.

\subsection{Practical implications}

Further to the theoretical contributions, there are a few practical implications of this research study. First, since the research findings confirm that the independent-self promotes competitive 
orientation; organizations should implement necessary strategies to reduce the rivalry that arises between employees due to the independent self-construal of some employees. This can be done by emphasizing the importance of relationships through task-interdependency and group goals, where employees have to work together rather than concentrating exclusively on individual work. Meanwhile, organizations should link group goals with performance appraisals. In this regard, human resource policies for incentives should not be based on individual performance but rather, on group goals. Furthermore, managers can encourage a cooperative work environment that reduces competition among employees and increases the exchange of ideas within the organization. Organizations could also implement a screening process for their employees using instruments such as the self-concept scale, so that managers can hire employees with higher levels of relational and collective selves.

\subsection{Limitations and directions for further research}

Although this research study makes several original contributions, it does have several limitations. First, the researcher collected cross sectional data using self-reported measures. Although the researcher took steps to mitigate common method bias, future research can redesign the study and collect longitudinal data. Second, since the study collected data from the banking industry and from managers, there is a concern regarding the generalizability of the results to other industries and to other job designations. In order to apply the results to other industries, it is important to test these relationships in other industrial contexts. Third, the current study only considered self-construal dimensions as antecedents of competitive orientation, whereas there could be other factors that could influence competitive orientation as well. Moreover, only a limited number of studies have addressed the mechanisms by which psychological variables such as self-construal impact ethical decision-making. To address these issues, future researchers can advance this model by suggesting and testing mediating and moderating pathways. One possible suggestion is the mediating mechanism of the psychological variable at the other end of the continuum, that is, cooperative orientation.

\section{References}

Abraham, J. and Pane, M.M. (2014), "Corruptive tendencies, conscientiousness, and collectivism", Procedia-Social and Behavioral Sciences, Vol. 153, pp. 132-147.

Albouza (2021), "Factorial validation and measurement invariance of the French version of the multidimensional competitive orientation inventory (FVMCOI) in the sport field", Pratiques Psychologiques, Vol. 27 No. 2, pp. 107-129.

Barigozzi, F., Garella, P.G. and Peitz, M. (2009), "With a little help from my enemy: comparative advertising as a signal of quality", Journal of Economics and Management Strategy, Vol. 18 No. 4, pp. 1071-1094.

Baron, R.M. and Kenny, D.A. (1986), "The moderator-mediator variable distinction in social psychological research: conceptual, strategic, and statistical considerations", Journal of Personality and Social Psychology, Vol. 51 No. 6, p. 1173.

Barreto, M. and Ellemers, N. (2000), "You can't always do what you want: social identity and selfpresentational determinants of the choice to work for a low-status group", Personality and Social Psychology Bulletin, Vol. 26 No. 8, pp. 891-906.

Bellé, N. and Cantarelli, P. (2017), "What causes unethical behavior? A meta-analysis to set an agenda for public administration research", Public Administration Review, Vol. 77 No. 3, pp. 327-339.

Benzi, N. (2016), "Philosophy in verse: competition and early greek philosophical thought", (Doctoral Dissertation, Durham University).

Beu, D.S., Buckley, M.R. and Harvey, M.G. (2003), "Ethical decision-making: a multidimensional construct", Business Ethics: A European Review, Vol. 12 No. 1, pp. 88-107.

\section{The mediating role of competitive orientation}


EJMS

27,1

54

Brewer, M.B. and Gardner, W. (1996), "Who is this 'We'? Levels of collective identity and selfrepresentations”, Journal of Personality and Social Psychology, Vol. 71 No. 1, pp. 83-93.

Brutus, S. and Greguras, G.J. (2008), "Self-construals, motivation, and feedback-seeking behaviors", International Journal of Selection and Assessment, Vol. 16 No. 3, pp. 282-291.

Bull, M. and Ridley-Duff, R. (2019), "Towards an appreciation of ethics in social enterprise business models", Journal of Business Ethics, Vol. 159 No. 3, pp. 619-634.

Carnevale, J.B., Huang, L. and Paterson, T. (2019), "LMX-differentiation strengthens the prosocial consequences of leader humility: an identification and social exchange perspective", Journal of Business Research, Vol. 96, pp. 287-296.

Central Bank of Sri Lanka (2018), "Annual report 2018”, available at: https://www.cbsl.gov.lk/en/ publications/economic-and-financial-reports/annual-reports/annual-report-2018 (accessed 20 August 2021).

Chen, X.P., Xie, X. and Chang, S. (2011), "Cooperative and competitive orientation among Chinese people: scale development and validation", Management and Organization Review, Vol. 7 No. 2 , pp. 353-379.

Cojuharenco, I., Shteynberg, G., Gelfand, M. and Schminke, M. (2012), "Self-construal and unethical behavior", Journal of Business Ethics, Vol. 109 No. 4, pp. 447-461.

Conway, J.M. and Lance, C.E. (2010), "What reviewers should expect from authors regarding common method bias in organizational research", Journal of Business and Psychology, Vol. 25 No. 3, pp. 325-334.

Cross, S.E. and Madson, L. (1997), "Models of the self: self-construals and gender", Psychological Bulletin, Vol. 122 No. 1, pp. 5-37.

Cross, S.E. and Morris, M.L. (2003), "Getting to know you: the relational self-construal, relational cognition, and well-being", Personality and Social Psychology Bulletin, Vol. 29 No. 4, pp. 512-523.

Cross, S.E., Bacon, P.L. and Morris, M.L. (2000), "The relational-interdependent self-construal and relationships", Journal of Personality and Social Psychology, Vol. 78 No. 4, pp. 791-808.

Cross, S.E., Morris, M.L. and Gore, J.S. (2002), "Thinking about oneself and others: the relationalinterdependent self-construal and social cognition”, Journal of Personality and Social Psychology, Vol. 82 No. 3, pp. 399-418.

Cross, S.E., Hardin, E.E. and Gercek-Swing, B. (2011), "The what, how, why, and where of selfconstrual”, Personality and Social Psychology Review, Vol. 15 No. 2, pp. 142-179.

Deng, H., Lam, C.K., Guan, Y. and Wang, M. (2020), "My fault or yours? Leaders' dual reactions to abusive supervision via rumination depend on their independent self-construal", Personnel Psychology, Vol. 75 No. 4, pp. 773-798, doi: 10.1111/peps.12430.

Deutsch, M. (1949), "A theory of co-operation and competition", Human Relations, Vol. 2 No. 2, pp. 129-152.

Deutsch, M. (1962), “Cooperation and trust: some theoretical notes”, in Jones, M. (Ed.), Nebraska Symposium on Motivation, University of Nebraska Press, Lincoln, pp. 275-320.

Deutsch, M. (2006), "Cooperation and competition", in Deutsch, M., Coleman, P.T. and Marcus, E.C. (Eds), The Handbook of Conflict Resolution: Theory and Practice, 2nd ed., Jossey-Bass, San Francisco, CA, pp. 23-42.

Dhandra, T.K. and Park, H.J. (2017), "Self-construal as an antecedent of ethical ideology", Journal of International Trade and Commerce, Vol. 13 No. 4, pp. 1-16.

Ferenczi, N., Marshall, T.C. and Bejanyan, K. (2017), "Are sex differences in antisocial and prosocial Facebook use explained by narcissism and relational self-construal?", Computers in Human Behavior, Vol. 77, pp. 25-31.

Fischbacher, U. and Föllmi-Heusi, F. (2013), "Lies in disguise — an experimental study on cheating", Journal of the European Economic Association, Vol. 11 No. 3, pp. 525-547. 
Freeman, M.A. (1997), "Demographic correlates of individualism and collectivism: a study of social values in Sri Lanka”, Journal of Cross-Cultural Psychology, Vol. 28 No. 3, pp. 321-341.

Fritzsche, D. and Oz, E. (2007), "Personal values' influence on the ethical dimension of decisionmaking", Journal of Business Ethics, Vol. 75 No. 4, pp. 335-344.

Gabriel, S. and Gardner, W.L. (1999), "Are there 'his' and 'hers' types of interdependence? The implications of gender differences in collective versus relational interdependence for affect, behavior, and cognition”, Journal of Personality and Social Psychology, Vol. 77 No. 3, pp. 642-655.

Gelfand, M.J., Major, V.S., Raver, J.L., Nishii, L.H. and O’Brien, K. (2006), "Negotiating relationally: the dynamics of the relational self in negotiations", Academy of Management Review, Vol. 31 No. 2, pp. $427-451$.

Gino, F. and Galinsky, A.D. (2012), "Vicarious dishonesty: when psychological closeness creates distance from one's moral compass", Organizational Behavior and Human Decision Processes, Vol. 119 No. 1, pp. 15-26.

Gino, F., Schweitzer, M.E., Mead, N.L. and Ariely, D. (2011), "Unable to resist temptation: how selfcontrol depletion promotes unethical behavior", Organizational Behavior and Human Decision Processes, Vol. 115 No. 2, pp. 191-203.

Gollwitzer, M. and Bücklein, K. (2007), “Are 'we' more punitive than 'me'? self-construal styles, justicerelated attitudes, and punitive judgments”, Social Justice Research, Vol. 20 No. 4, pp. 457-478.

Goncalo, J.A. and Staw, B.M. (2006), "Individualism-collectivism and group creativity", Organizational Behavior and Human Decision Processes, Vol. 100 No. 1, pp. 96-109.

Grant, A.M. (2008), "Does intrinsic motivation fuel the prosocial fire? Motivational synergy in predicting persistence, performance, and productivity", Journal of Applied Psychology, Vol. 93 No. 1 , pp. $48-58$.

Hair, J.F., Hult, G.T.M., Ringle, C.M. and Sarstedt, M. (2017), A Primer on Partial Least Squares Structural Equation Modeling (PLS-SEM), 2nd ed., Sage Publications, Thousand Oaks.

Hair, J.F., Risher, J.J., Sarstedt, M. and Ringle, C.M. (2019), "When to use and how to report the results of PLS-SEM", European Business Review, Vol. 31 No. 1, pp. 1-24.

Henseler, J., Ringle, C.M. and Sinkovics, R.R. (2009), "The use of partial least squares path modeling in international marketing", New Challenges to International Marketing, Emerald Group Publishing.

Horney, K. (1937), The Neurotic Personality of Our Time, Norton, New York.

Hoshino-Browne, E., Zanna, A.S., Spencer, S.J., Zanna, M.P., Kitayama, S. and Lackenbauer, S. (2005), "On the cultural guises of cognitive dissonance: the case of easterners and westerners", Journal of Personality and Social Psychology, Vol. 89 No. 3, pp. 294-310.

Hoyt, C.L. and Price, T.L. (2015), "Ethical decision making and leadership: merging social role and selfconstrual perspectives", Journal of Business Ethics, Vol. 126 No. 4, pp. 531-539.

Ives, J.C., Neese, K., Downs, N., Root, H. and Finnerty, T. (2020), "The effects of competitive orientation on performance in competition", The Sport Journal, Vol. 41 No. 2, available at: https:// thesportjournal.org/article/the-effects-of-competitive-orientation-on-performance-incompetition/.

Jayawardena-Willis, T.S., Pio, E. and McGhee (2021), "The divine states (brahmaviharas) in managerial ethical decision-making in organisations in Sri Lanka: an interpretative phenomenological analysis", Journal of Business Ethics, Vol. 168, pp. 151-171.

Johnson, R.E. and Chang, C.H. (2006), "I' is to continuance as 'we' is to affective: the relevance of the self-concept for organizational commitment", Journal of Organizational Behavior: The International Journal of Industrial, Occupational and Organizational Psychology and Behavior, Vol. 27 No. 5, pp. 549-570.

Johnson, D.W. and Johnson, R. (1991), Learning Together and Alone: Cooperative, Competitive, and Individualistic Learning, 5th ed., Allyn \& Bacon, Boston.
The mediating role of competitive orientation 
EJMS

27,1

56

Johnson, R.E. and Lord, R.G. (2010), "Implicit effects of justice on self-identity", Journal of Applied Psychology, Vol. 95 No. 4, pp. 681-695.

Jones, T.M. (1991), "Ethical decision making by individuals in organizations: an issue-contingent model", Academy of Management Review, Vol. 16 No. 2, pp. 366-395.

Kashima, E.S. and Hardie, E.A. (2000), "The development and validation of the relational, individual, and collective self-aspects (RIC) scale", Asian Journal of Social Psychology, Vol. 3 No. 1, pp. 19-48.

Kashima, Y., Yamaguchi, S., Kim, U., Choi, S.C., Gelfand, M.J. and Yuki, M. (1995), “Culture, gender, and self: a perspective from individualism-collectivism research", Journal of Personality and Social Psychology, Vol. 69 No. 5, pp. 925-937.

Kilduff, G.J. and Galinsky, A.D. (2017), "The spark that ignites: mere exposure to rivals increases machiavellianism and unethical behavior", Journal of Experimental Social Psychology, Vol. 69, pp. 156-162.

Kilduff, G.J., Elfenbein, H.A. and Staw, B.M. (2010), "The psychology of rivalry: a relationally dependent analysis of competition", Academy of Management Journal, Vol. 53 No. 5, pp. 943-969.

Kilduff, G.J., Galinsky, A.D., Gallo, E. and Reade, J.J. (2016), "Whatever it takes to win: rivalry increases unethical behavior", Academy of Management Journal, Vol. 59 No. 5, pp. 1508-1534.

Kim, H. and Markus, H.R. (1999), "Deviance or uniqueness, harmony or conformity? A cultural analysis", Journal of Personality and Social Psychology, Vol. 77 No. 4, p. 785.

Kish-Gephart, J.J., Harrison, D.A. and Treviño, L.K. (2010), "Bad apples, bad cases, and bad barrels: meta-analytic evidence about sources of unethical decisions at work", Journal of Applied Psychology, Vol. 95 No. 1, pp. 1-35.

Kitayama, S., Uchida, Y. and Norasakkunkit, V. (2004), "Cultural constructions of happiness: theory and empirical evidence”, Journal of Happiness Studies, Vol. 5, pp. 223-239.

Kitayama, S., Mesquita, B. and Karasawa, M. (2006), "Cultural affordances and emotional experience: socially engaging and disengaging emotions in Japan and the United States", Journal of Personality and Social Psychology, Vol. 91 No. 5, p. 890.

Kohn, A. (1986), No Contest: the Case Against Competition, Houghton Mifflin, Boston.

Krejcie, R.V. and Morgan, D.W. (1970), "Determining sample size for research activities”, Educational and Psychological Measurement, Vol. 30 No. 3, pp. 607-610.

Kumarasinghe, S. and Hoshino, Y. (2010), "The role and perceptions of middle managers and their influence on business performance: the case of Sri Lanka”, International Business Research, Vol. 3 No. 4, pp. 3-16.

Latan, H., Jabbour, C.J.C. and de Sousa Jabbour, A.B.L. (2017), "Ethical awareness, ethical judgment and whistleblowing: a moderated mediation analysis", Journal of Business Ethics, Vol. 155, pp. 289-304, doi: 10.1007/s10551-017-3534-2.

Lee, J.J., Hardin, A.E., Parmar, B. and Gino, F. (2019), "The interpersonal costs of dishonesty: how dishonest behavior reduces individuals' ability to read others' emotions", Journal of Experimental Psychology: General, Vol. 148 No. 9, pp. 1557-1574.

Li, Y., Feng, T. and Jiang, W. (2018), "How competitive orientation influences unethical decisionmaking in clinical practices?”, Asian Nursing Research, Vol. 12 No. 3, pp. 182-189.

Lind, E.A. (2001), "Fairness heuristic theory: justice judgments as pivotal cognitions in organizational relations", in Greenberg, J. and Cropanzano, R. (Eds), Advances in Organizational Justice, New Lexington Press, San Francisco, CA, pp. 56-88.

Lindner, J.R., Murphy, T.H. and Briers, G.E. (2001), "Handling nonresponse in social science research", Journal of Agricultural Education, Vol. 42 No. 4, pp. 43-53.

Markus, H. (1977), "Self-schemata and processing information about the self", Journal of Personality and Social Psychology, Vol. 35 No. 2, pp. 63-78. 
Markus, H.R. and Kitayama, S. (1991), "Culture and the self: implications for cognition, emotion, and motivation”, Psychological Review, Vol. 98 No. 2, pp. 224-253.

Mead, M. (1976), Cooperation and Competition Among Primitive People, Beacon, Boston, MA.

Nancarrow, C., Brace, I. and Wright, L.T. (2001), “Tell me lies, tell me sweet little lies': dealing with socially desirable responses in market research", The Marketing Review, Vol. 2 No. 1, pp. 55-69.

Nebel, S., Schneider, S. and Rey, G.D. (2016), "From duels to classroom competition: social competition and learning in educational videogames within different group sizes", Computers in Human Behavior, Vol. 55, pp. 384-398.

Peterson, D. (2004), "Perceived leader integrity and ethical intentions of subordinates", Leadership and Organization Development Journal, Vol. 25 No. 1, pp. 7-23.

Podsakoff, P.M., MacKenzie, S.B., Lee, J.Y. and Podsakoff, N.P. (2003), "Common method biases in behavioral research: a critical review of the literature and recommended remedies", Journal of Applied Psychology, Vol. 88 No. 5, pp. 879-903.

Ralston, D.A., Egri, C.P., Furrer, O., Kuo, M.H., Li, Y., Wangenheim, F. and Weber, M. (2014), "Societallevel versus individual-level predictions of ethical behavior: a 48-society study of collectivism and individualism", Journal of Business Ethics, Vol. 122 No. 2, pp. 283-306.

Rapoport, A., Chammah, A.M. and Orwant, C.J. (1965), Prisoner's Dilemma, University of Michigan Press, Ann Arbor, MI.

Rest, J.R. (1986), Moral Development: Advances in Research and Theory, Praeger, New York.

Rhodes, A. and Wilson, C.M. (2018), "False advertising", The Rand Journal of Economics, Vol. 49 No. 2, pp. 348-369.

Rigdon, M.L. and D'Esterre, A.P. (2015), “The effects of competition on the nature of cheating behavior", Southern Economic Journal, Vol. 81 No. 4, pp. 1012-1024.

Roney, C. and Soicher, H.M. (2021), "Work and well-being: collective and individual self-concept, job commitment, citizenship behavior, and autonomy as predictors of overall life satisfaction", The Journal of Social Psychology, pp. 1-12, doi: 10.1080/00224545.2021.1915230.

Saracevic, S. and Schlegelmilch, B.B. (2021), "The impact of social norms on pro-environmental behavior: a systematic literature review of the role of culture and self-construal", Sustainability, Vol. 13 No. 9, p. 5156, doi: 10.3390/su13095156.

Saunders, M., Lewis, P. and Thornhill, A. (2009), Research Methods for Business Students, 7th ed., Prentice-Hall, London.

Schwieren, C. and Weichselbaumer, D. (2010), "Does competition enhance performance or cheating? A laboratory experiment", Journal of Economic Psychology, Vol. 31 No. 3, pp. 241-253.

Sedikides, C. and Brewer, M.B. (2015), Individual Self, Relational Self, and Collective Self, Psychology Press, Philadelphia.

Simpson, B., White, K. and Laran, J. (2018), "When public recognition for charitable giving backfires: the role of independent self-construal", Journal of Consumer Research, Vol. 44 No. 6, pp. 1257-1273.

Simpson, B., Robertson, J.L. and White, K. (2020), "How co-creation increases employee corporate social responsibility and organizational engagement: the moderating role of self-construal", Journal of Business Ethics, Vol. 166 No. 2, pp. 331-350.

Singelis, T.M. (1994), "The measurement of independent and interdependent self-construals", Personality and Social Psychology Bulletin, Vol. 20 No. 5, pp. 580-591.

Swab, R.G. and Johnson, P.D. (2019), "Steel sharpens steel: a review of multilevel competition and competitiveness in organizations", Journal of Organizational Behavior, Vol. 40 No. 2, pp. 147-165. 
EJMS

27,1

Transparency International. (2020), “Corruption perceptions index 2019”, available at: https:/images. transparencycdn.org/images/CPI2020_Report_EN_0802-WEB-1.pdf (accessed 8 August 2020).

Treviño, L.K., Weaver, G.R. and Reynolds, S.J. (2006), "Behavioral ethics in organizations: a review", Journal of Management, Vol. 32 No. 6, pp. 951-990.

Treviño, L.K., Den Nieuwenboer, N.A. and Kish-Gephart, J.J. (2014), "(Un)ethical behavior in organizations”, Annual Review of Psychology, Vol. 65, pp. 635-660.

Triandis, H.C. (1989), "The self and social behavior in differing cultural contexts", Psychological Review, Vol. 96 No. 3, pp. 506-520.

Triandis, H.C. (1996), "The psychological measurement of cultural syndromes”, American Psychologist, Vol. 51 No. 4, pp. 407-415.

Triandis, H.C., Carnevale, P., Gelfand, M., Robert, C., Wasti, S.A., Probst, T. and Schmitz, P. (2001), "Culture and deception in business negotiations: a multilevel analysis", International Journal of Cross Cultural Management, Vol. 1 No. 1, pp. 73-90.

Turner, J.C., Hogg, M.A., Oakes, P.J., Reicher, S.D. and Wetherell, M.S. (1987), Rediscovering the Social Group: A Self-Categorization Theory, Basil Blackwell, New York.

Tyler, T.R. and Blader, S.L. (2003), "The group engagement model: procedural justice, social identity, and cooperative behavior", Personality and Social Psychology Review, Vol. 7 No. 4, pp. 349-361.

Utz, S. (2004), "Self-construal and cooperation: is the interdependent self more cooperative than the independent self?", Self and Identity, Vol. 3 No. 3, pp. 177-190.

van Prooijen, J.W. and van den Bos, K. (2009), "We blame innocent victims more than I do: selfconstrual level moderates responses to just-world threats", Personality and Social Psychology Bulletin, Vol. 35 No. 11, pp. 1528-1539.

Wan, L.C., Hui, M.K. and Qiu, Y.C. (2021), "Tourist misbehavior: psychological closeness to fellow consumers and informal social control”, Tourism Management, Vol. 83, p. 104258, doi: 10.1016/j. tourman.2020.104258.

Wiekens, C.J. and Stapel, D.A. (2008), "I versus we: the effects of self-construal level on diversity", Social Cognition, Vol. 26 No. 3, pp. 368-377.

Yang, H., Sanders, K. and Bumatay, C.P. (2012), "Linking perceptions of training with organizational commitment: the moderating role of self-construals", European Journal of Work and Organizational Psychology, Vol. 21 No. 1, pp. 125-149.

Yang, H., Van Rijn, M.B. and Sanders, K. (2020), "Perceived organizational support and knowledge sharing: employees' self-construal matters", The International Journal of Human Resource Management, Vol. 31 No. 17, pp. 2217-2237.

Yuki, M., Maddux, W.W., Brewer, M.B. and Takemura, K. (2005), "Cross-cultural differences in relationshipand group-based trust", Personality and Social Psychology Bulletin, Vol. 31 No. 1, pp. 48-62.

Zhang, J., Chen, Y., Liu, C.-E., Liu, T. and He, W. (2021), "Work-related identity discrepancy and employee innovation behavior: the role of intrinsic motivation and self-construal", Chinese Management Studies, Vol. 15 No. 5, pp. 1143-1156, doi: 10.1108/CMS-02-2021-0051.

Zhang, Y. and Mittal, V. (2007), "The attractiveness of enriched and impoverished options: culture, self-construal, and regulatory focus", Personality and Social Psychology Bulletin, Vol. 33 No. 4, pp. 588-598.

Zhou, J., Chi, W. and Zhu, W. (2021), "No good deed is too small: field experimental studies of different self-identities and workplace saving behavior", Chinese Management Studies, Vol. ahead-ofprint No. ahead-of-print, doi: 10.1108/CMS-12-2020-0529.

\section{Further reading}

Beekun, R.I., Hamdy, R., Westerman, J.W. and HassabElnaby, H.R. (2008), "An exploration of ethical decision-making processes in the United States and Egypt", Journal of Business Ethics, Vol. 82 No. 3, pp. 587-605. 
Casali, G.L. and Perano, M. (2021), "Forty years of research on factors influencing ethical decisionmaking: establishing a future research agenda”, Journal of Business Research, Vol. 132, pp. 614-630.

Craft, J.L. (2013), “A review of the empirical ethical decision-making literature: 2004-2011”, Journal of Business Ethics, Vol. 117 No. 2, pp. 221-259.

O'Fallon, M.J. and Butterfield, K.D. (2005), "A review of the empirical ethical decision-making literature: 1996-2003”, Journal of Business Ethics, Vol. 59 No. 4, pp. 375-413.

O'Fallon, M.J. and Butterfield, K.D. (2011), "Moral differentiation: exploring boundaries of the "monkey see, monkey do" perspective", Journal of Business Ethics, Vol. 102 No. 3, pp. 379-399.

O'Fallon, M.J. and Butterfield, K.D. (2013), "A review of the empirical ethical decision-making literature: 1996-2003", Advances in Business Ethics Research (A Journal of Business Ethics Book Series), in Michalos, A. and Poff, D. (Eds), Citation Classics from the Journal of Business Ethics, Springer, Dordrecht, Vol. 2.

Treviño, L.K. and Weaver, G.R. (2003), Managing Ethics in Business Organizations: A Social Science Perspective, Stanford Business Books, Stanford, CA.

Treviño, L.K. and Youngblood, S.A. (1990), "Bad apples in bad barrels: a causal analysis of ethical decision-making behavior", Journal of Applied Psychology, Vol. 75 No. 4, pp. 378-385.

\section{Annexure 1}

\section{Individual level}

(1) I thrive on opportunities to demonstrate that my abilities or talents are better than those of other people.

(2) I have a strong need to know how I stand in comparison to my coworkers.

(3) I often compete with my friends.

(4) I feel best about myself when I perform better than others.

(5) I often find myself pondering over the ways that I am better or worse off than other people around me.

\section{Relational level}

(1) If a friend was having a personal problem, I would help him/her even if it meant sacrificing my time or money.

(2) I value friends who are caring, empathic individuals.

(3) It is important to me that I uphold my commitments to significant people in my life.

(4) Caring deeply about another person such as a close friend or relative is important to me.

(5) Knowing that a close other acknowledges and values the role that I play in their life makes me feel like a worthwhile person.

\section{Collective-level}

(1) Making a lasting contribution to groups that I belong to, such as my work organization, is very important to me.

(2) When I become involved in a group project, I do my best to ensure its success. 
EJMS

27,1

60
(3) I feel great pride when my team or group does well, even if I'm not the main reason for its success.

(4) I would be honored if I were chosen by an organization or club that I belong to, to represent them at a conference or meeting.

(5) When I'm part of a team, I am concerned about the group as a whole instead of whether individual team members like me or whether I like them.

\section{Annexure 2}

(1) I would be willing to pass on incorrect information to others if it gives me a competitive advantage.

(2) I would be willing to engage in what some might say are sneaky (cunning) tactics.

(3) I would be willing to do a favor for others if that would get me special treatment in this competition.

(4) I would justify any misrepresenting of facts/information in order to safeguard the integrity.

(5) I will justify the decisions that could potentially harm others while benefitting my own plan.

(6) In order to achieve my goal, I will justify the acting in non-compliance of laws, regulations, standards, and business codes if it is certain that no one will find out.

\section{Corresponding author}

D.M. Sachinthanee Dissanayake can be contacted at: sachinthanee@sjp.ac.lk

For instructions on how to order reprints of this article, please visit our website: 